\title{
Chronic nicotine exposure induces a long-lasting and pathway-specific facilitation of LTP in the amygdala
}

\author{
Yan-You Huang, ${ }^{1}$ Eric R. Kandel, ${ }^{1,2,3}$ and Amir Levine ${ }^{1,4}$ \\ ${ }^{1}$ Center for Neurobiology and Behavior, College of Physicians and Surgeons of Columbia University, New York State Psychiatric \\ Institute, New York, New York 10032, USA; ${ }^{2}$ Kavli Institute for Brain Science, New York, New York 10032, USA; ${ }^{3}$ Howard \\ Hughes Medical Institute, New York, New York 10032, USA
}

\begin{abstract}
Nicotine, in the form of tobacco, is the most commonly used drug of abuse. In addition to its rewarding properties, nicotine also affects many cognitive and emotional processes that involve several brain regions, including hippocampus and amygdala. Long-term changes in synaptic strength in these brain regions after drug exposure may be importantly correlated with behavioral changes induced by nicotine. Here, we study the effect of chronic oral administration of nicotine on the long-term synaptic potentiation in the amygdala, a key structure for emotional memory. We find that oral administration of nicotine for $7 \mathrm{~d}$ produces a significant enhancement of LTP in the amygdala. This facilitation is pathway specific: Nicotine selectively facilitates LTP in the cortical-lateral amygdala pathway, but not the thalamic-lateral and the lateral-basolateral synaptic pathway. The synaptic facilitation induced by a 7-d exposure to nicotine is long-lasting, it persists for $72 \mathrm{~h}$ after cessation of nicotine but decays $8 \mathrm{~d}$ after its cessation. In contrast, a shorter exposure of nicotine $(24 \mathrm{~h})$ induces only a short-lasting facilitation of synaptic plasticity that dissipates 24 and $72 \mathrm{~h}$ after cessation of nicotine. The facilitation of LTP in the amygdala after exposure to nicotine is mediated by removal of GABAergic inhibition, is dependent on the activation NMDA receptors, and can be prevented by blocking either $\boldsymbol{\alpha} 7$ or $\boldsymbol{\beta} 2 \mathrm{nACh}$ receptors. Our results indicate that chronic exposure to nicotine can promote the induction of long-lasting modifications of synapses in a specific pathway in the amygdala.These changes in synaptic plasticity may contribute to the complex neural adaptations and behaviors caused by nicotine.
\end{abstract}

Nicotine derived from tobacco is one of the most commonly used drugs of abuse. However, the cellular mechanisms underlying the effects of nicotine are not well understood. Previous studies on the neural mechanism underlying nicotine addiction have mainly focused on the effects of nicotine in the brain reward system such as the ventral tegemental area (VTA) and nucleus accumbens (Nac) (Mansvelder and McGehee 2000, 2002; Dani et al. 2001). In contrast, the effects of nicotine on learning-related emotional systems are less well known.

Nicotine is known to enhance many cognitive processes. For instance, nicotine enhances spatial working memory in the radial-arm maze and the Morris water maze in rodents (Levin 1992; Socci et al.1995). Nicotine also facilitates fear conditioning, such as contextual fear conditioning and trace fear conditioning (Gould and Higgins 2003; Gould et al. 2004; Davis et al. 2006). In addition, nicotine dependence (tobacco use) is related to the development of certain forms of anxiety disorders (Sonntag et al. 2000; Morissette et al. 2007). All of these nicotine-induced behavioral changes involve both the hippocampus and the amygdala. Several previous studies have shown that nicotine facilitates the induction of long-term potentaition (LTP) in the hippocampus. Bath application or systemic administration of nicotine enhances LTP in the CA1 region and in the dentate gyrus in the hippocampus (Fujii et al. 1999, 2000; Welsby et al. 2007). Nicotine converts short-term potentiation (STP) into LTP in the hippocampal CA1 region (Welsby et al. 2006) and reverts the impairment in LTP induction induced by a cholinergic lesion (Yamazaki et al. 2002). In contrast, the effect of chronic, in vivo exposure to nicotine on synaptic plasticity in the amygdala is not known.

\footnotetext{
${ }^{4}$ Corresponding author.
}

E-mail ama146@columbia.edu; fax (212) 543-6031.

Article is online at http://www.learnmem.org/cgi/doi/10.1101//m.975308.
The basolateral amygdala (BA) complex, which contains the lateral, basolateral, and basomedial nuclei, is thought to be the site for the formation and storage of fear memory. The synaptic facilitation produced by fear conditioning and the LTP elicited by electrical stimulation in the amygdala are thought to share a common synaptic mechanism (Rogan et al. 1997; Huang and Kandel 1998; Tsvetkov et al. 2002; Schroeder and ShinickGallagher 2005). It is therefore of interest to explore the changes induced by nicotine on synaptic plasticity in that region.

The fear circuit in the amygdala contains different synaptic pathways, and these pathways may play different roles in fear memory. We asked first: Does nicotine administration affect synaptic plasticity in all pathways in amygdala, or does it selectively affect some synaptic pathways and not others? Second, since nicotine activates various subtypes of nicotine acetylcholine receptors (nAChRs), which functional receptor subtype mediates the effect of nicotine in the amygdala? Third, since the activation of NMDA receptors is critical for the induction of LTP in the amygdala and for amygdala-dependent fear memory (Bauer et al. 2002), is the nicotine effect mediated by NMDA receptors? Finally, we wanted to determine the time course of the plastic changes induced by chronic nicotine exposure: How long do the nicotine-induced synaptic changes last after cessation of nicotine, and what is the difference between short-term and longterm exposure to nicotine on these plastic changes?

\section{Results}

Pathway specific facilitation of nicotine

In most studies of LTP in amygdala slices, GABAergic antagonist picrotoxin (PTX) or bicuculline are administered in the bath to block the tonic inhibition of GABAergic interneuron (Huang and Kandel 1998; Rammes et al. 2000; Tsvetkov et al. 2002). To examine the nicotine effect on synaptic plasticity in general, we 
checked LTP with intact GABAergic inhibition (without PTX), followed later by measurement of LTP in the presence of GABAergic antagonist in the bath.

In the cortical-lateral amygdala (LA) pathway, which transmits sensory information during fear conditioning, with inhibition intact, repeated highfrequency stimulation (HFS, $6 \times 100$ $\mathrm{Hz}$ ) only induces a modest LTP $(117 \pm 6 \%, n=8$, measured 60 min after the first tetanus) in controls (mice drinking tap water). However, in slices from mice treated with nicotine $(10 \mu \mathrm{g} / \mathrm{mL})$ for $7 \mathrm{~d}$, the same tetanic stimulation induces a much greater amplitude of LTP $(140 \pm 5 \%, n=10$, measured $60 \mathrm{~min}$ after tetanization) (Fig. 1A2), which is significantly larger than LTP in control slices $(P<0.01)$. The facilitation of LTP induced by nicotine is activity dependent, and there is no facilitation of LTP by a single tetanic stimulation $(1 \times 100$ $\mathrm{Hz}$; control: $110 \pm 6 \%, n=6$; nicotine: $104 \pm 4 \%, n=6 ; P>0.05$ ) (Fig. 1B). Nicotine-induced enhancement of LTP is also dose dependent. Exposure of a lower dose of nicotine $(2 \mu \mathrm{g} / \mathrm{mL})$ did not produce any significant increase of LTP $(122 \pm 5 \%, n=5 ; P>0.05)$, and a higher dose of nicotine $(25 \mu \mathrm{g} / \mathrm{mL})$ produced a smaller increase of LTP than 10 $\mu \mathrm{g} / \mathrm{mL}$ treatment $(133 \pm 3 \%, n=7)$ but is still significantly greater than LTP in control mice $(P<0.05)$. Thus, nicotineinduced facilitation of LTP in the amygdala shows an inverted U-shape dose response curve. Dose-dependent changes of LTP induced by 7-d nicotine exposure are shown in Figure 1C. The facilitation of LTP is not associated with the changes in the input-output curve in this pathway (Fig. 1D). Interestingly, nicotineinduced facilitation of LTP is pathway specific. In the pathway from thalamus (TH) to the LA (TH-LA), which conveys sensory information directly to the LA, the same tetanic stimulation did not induce significant LTP $(108 \pm 11 \%, n=6$; $P>0.05$ ) (Shin et al. 2006), and nicotine exposure did not produce any significant facilitation of LTP $(112 \pm 10 \%$, $n=7 ; P>0.05$ ) (Fig. 2A2). Similarly, nicotine treatment did not induce any significant facilitation of LTP in projec-

tive pathway from lateral (LA) to basolateral (BL) amygdala (nicotine: $122 \pm 9 \%, n=7$; control: $109 \pm 3 \%, n=6$; $P>0.05$ ) (Fig. 2B2). A comparison of plastic changes in the three different pathways is shown in Figure 2C. These results indicate that nicotineinduced facilitation of LTP in the amygdala circuitry is pathway specific and that the pathway from cortex to the LA is highly sensitive to nicotine-induced changes of synaptic plasticity.

Time course of nicotine-induced synaptic facilitation Persistence is an important feature of long-term synaptic potentiation. Different forms of LTP may have different underlying cellular and molecular mechanisms. In the hippocampus, facilitation induced by chronic nicotine exposure required $10 \mathrm{~d}$ of intraperitoneal (i.p) injections, and the facilitated LTP was significantly reduced $2 \mathrm{~d}$ after the cessation of nicotine (Yamazaki et al. 2006b). We were interested in determining how long the facilitation of LTP in the amygdala lasts after oral administration of nicotine. We first examined long-term exposure to nicotine. In these experiments, we administered nicotine for $7 \mathrm{~d}$ perorally (p.o.) and measured LTP $24 \mathrm{~h}, 72 \mathrm{~h}$, and $8 \mathrm{~d}$ after cessation of nicotine. We find that facilitation of LTP persisted $24 \mathrm{~h}$ after nicotine is stopped (nicotine: $139 \pm 8 \%, n=8$; control: 
A1

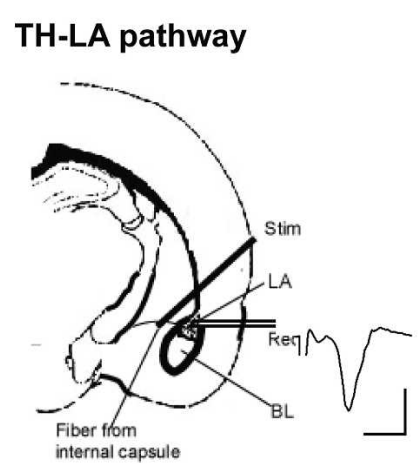

B1

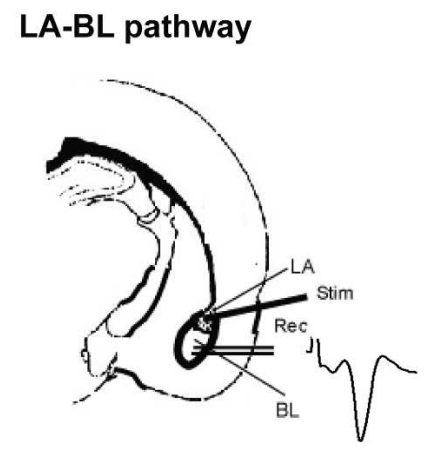

C

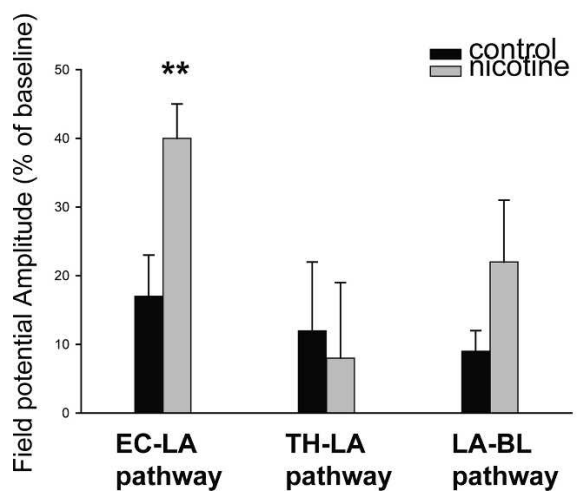

Figure 2. Nicotine-induced facilitation of LTP is pathway-specific. (A1) Schematic illustration of the stimulating and recording site of the TH-LA pathway. (A2) Nicotine administration for $7 \mathrm{~d}$ failed to facilitate LTP induced by HFS $(6 \times 100 \mathrm{~Hz})$ in this pathway. Closed squares indicate nicotine slices; open circles, control slices. (B1) Illustration of stimulating and recoding site from lateral-basolateral pathway. (B2) Nicotine administration (7 d) did not significantly facilitate LTP induced by HFS $(6 \times 100 \mathrm{~Hz})$ in this pathway. Closed squares indicate nicotine slices; open circles, control. (C) The histogram shows comparisons of the nicotine effect on LTP in three different synaptic pathways in the amygdala.

$116 \pm 5 \%, n=7 ; P<0.05)$ (Fig. 3A). Even $3 \mathrm{~d}(72 \mathrm{~h})$ after cessation of nicotine, LTP is still significantly greater than in control slices (nicotine: $140 \pm 8 \%$; control: $116 \pm 5 \% ; P<0.05$ ) (Fig. 3B). However, by $8 \mathrm{~d}$ after cessation of nicotine, the facilitation completely disappears, and LTP in these mice is not significantly different from that of controls (nicotine: $114 \pm 6 \%, n=7$; control: $117 \pm 8 \%, n=7 ; P>0.05$ ) (Fig. 3C). The changes in LTP after various days of nicotine cessation are shown in Figure 3D.

We next examined LTP in slices from a short exposure $(24 \mathrm{~h})$ to nicotine. Surprisingly, we find that the formation of LTP facilitation in the amygdala is rapid. In mice exposed to nicotine for only $1 \mathrm{~d}(24 \mathrm{~h})$, LTP in the amygdala is greatly enhanced (nicotine: $141 \pm 6 \%, n=7$; control: $116 \pm 5 \%$, $n=7 ; P<0.05$ ) (Fig. 4A), and the increase in LTP in mice exposed to nicotine for $24 \mathrm{~h}$ is not significantly different from that of 7-d exposure to nicotine $(P>0.05)$. However, we find that the persistence of LTP facilitation in mice treated with nicotine for $1 \mathrm{~d}$ and $7 \mathrm{~d}$ is different. In mice exposed to nicotine for $1 \mathrm{~d}$, LTP decays quickly and returns to control as early as $24 \mathrm{~h}$ after cessation of nicotine (nicotine: $117 \pm 8 \%, n=8$; control: $114 \pm 6 \%, n=7 ; P>0.05$ ) (Fig. $4 \mathrm{~B})$, and there is no facilitation of LTP at $72 \mathrm{~h}$ (nicotine: $114 \pm 7 \%, n=7$; control: $114 \pm 6, n=7 ; P>0.05$; Fig. 4 C). These results indicate that nicotine can produce different forms of LTP facilitation, depending on the exposure time. Longer exposure to nicotine produces more enduring facilitation of LTP in the amygdala, while short-term exposure to nicotine induces only a short-lasting facilitation of LTP, although the magnitude is surprisingly similar.

\section{The facilitation of LTP requires activation of nicotine $\alpha 7$ and $\beta 2$ $\mathrm{ACh}$ receptors}

In our experiments, slices were incubated in a slice chamber for $2-3 \mathrm{~h}$ before recording. Because the half-life of nicotine is $\sim 55 \mathrm{~min}$ (Miller et al. 1977), the effect we observed here is not a result of a direct action of residual nicotine in the brain. Chronic nicotine exposure may induce long-term alternations of nACh receptors and their signaling pathways. nAChRs are a multiple-gene family of ligand-gated ion channels that are involved in diverse brain functions. The density of $\beta 2$ - and $\alpha 7$-containing nAChRs is increased after chronic exposure to nicotine both in vivo and in vitro (Gaimarri et al. 2007). Ultrastructural studies have revealed the presence of both $\alpha 7$ and $\beta 2$ subreceptors in amygdala neurons (Hill Jr. et al. 1993; Klein and Yakel 2006). We asked the following: Is the activation of one or both of these receptor types required for nicotine-induced facilitation of LTP in the amygdala? We first examined the effect of a general nAChR antagonist macamylamine. When macamylamine $(20 \mu \mathrm{M})$ is present in the bath, the facilitation of LTP induced by chronic nicotine exposure $(10 \mu \mathrm{g} / \mathrm{mL}$ for $7 \mathrm{~d}$ ) was significantly reduced (nicotine: $150 \pm 4 \%, n=7$; nicotine + macamylamie: $126 \pm 4 \%$, $n=7 ; P<0.05$ ) (Fig. 5A). To determine whether nicotine-induced facilitation of LTP in the amygdala involves $\alpha 7 \mathrm{nACh}$ receptors, we applied the $\alpha 7$ antagonist methyllycacanitine (MLA, $10 \mu \mathrm{M}$ ) to the bath 20 min prior to the HFS. In the presence of MLA, the facilitated effect of nicotine in slices is blocked (nicotine: $149 \pm 4 \%$; nicotine + MLA: $118 \pm 4 \%$; $P<0.05$ ) (Fig. 5B). Simi- 
A

\section{$24 \mathrm{~h}$ after cessation of 7-day nicotine}

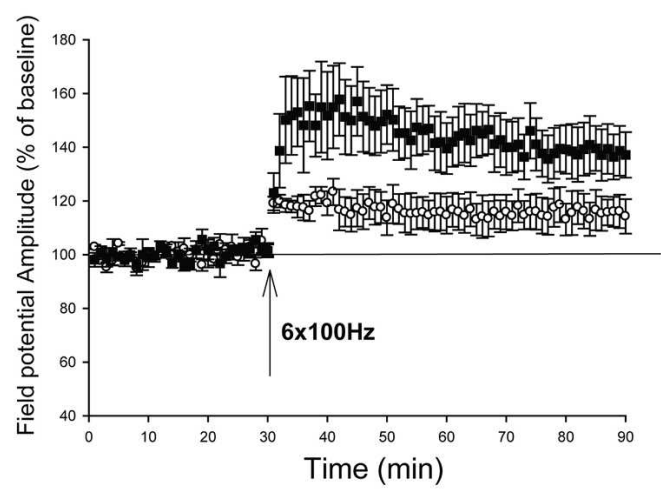

C

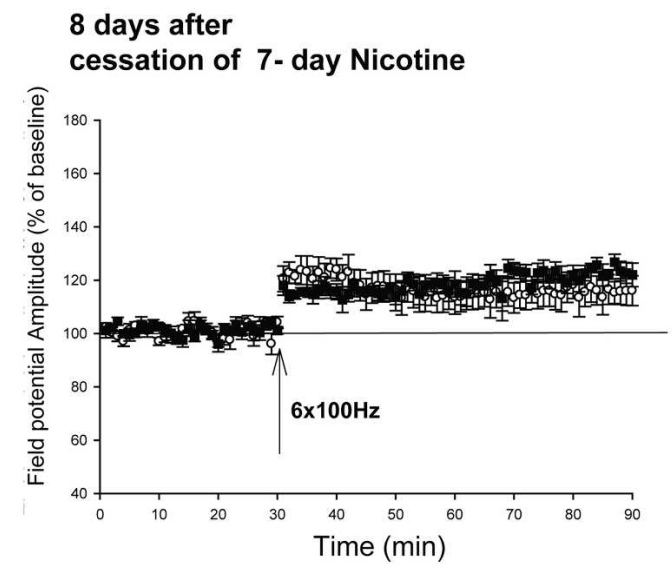

B

\begin{abstract}
$72 \mathrm{~h}$ after cessation of 7- day nicotine
\end{abstract}

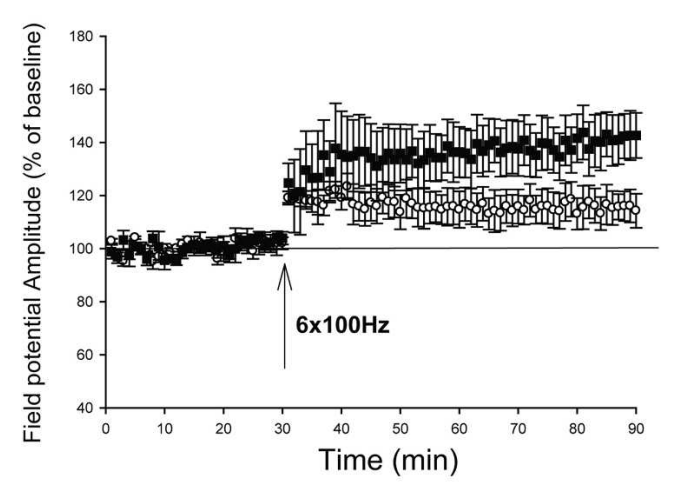

D

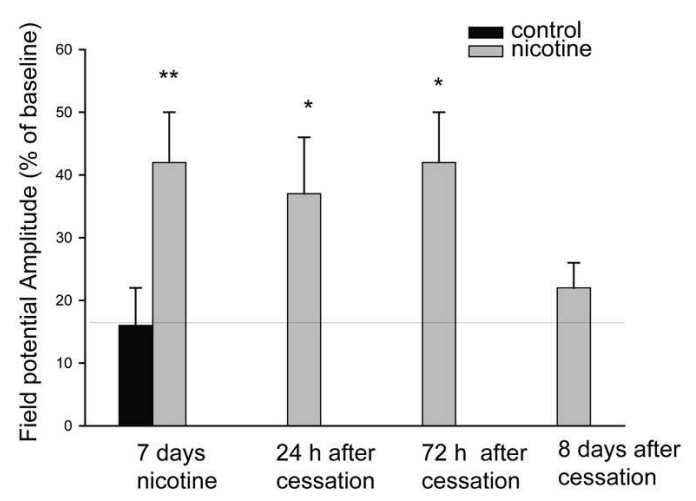

Figure 3. The time course of synaptic facilitation induced by 7-d nicotine administration. ( $A$ ) Twenty-four hours after cessation of nicotine exposure (7-d nicotine treatment followed by $1 \mathrm{~d}$ of water), LTP induced by HFS is still significantly greater than that in control experiments. Closed squares indicate nicotine water; open circles, water control. $(B)$ The facilitation of synaptic plasticity remains even at $72 \mathrm{~h}$ after cessation of nicotine exposure. (C) Eight days after cessation of nicotine, the facilitation of synaptic potentiation completely disappears. $(D)$ The histogram shows the synaptic facilitation (60 min after HFS) at different time points after the cessation of nicotine exposure $(7 \mathrm{~d}) .{ }^{*} P<0.05,{ }^{* \star} P<0.01$.

larly, bath application of the $\beta 2 \mathrm{nAChR}$ antagonist dihydeou- $\beta$ erythroidine hydromide $(\mathrm{D} \beta \mathrm{H}, 20 \mu \mathrm{M})$ also completely blocks the facilitated effect in slices of mice that are treated with nicotine (nicotine: $147 \pm 7 \%, n=7$; nicotine $+\mathrm{D} \beta \mathrm{H}, 118 \pm 7 \%$, $n=8 ; P<0.05)$ (Fig. 5C). The application of MLA $(20 \mu \mathrm{M})$ and or $\mathrm{D} \beta \mathrm{H}(20 \mu \mathrm{M})$ does not alter the baseline amplitude of field potentials in nicotine slices (data not shown). These results indicate that the facilitation effect of nicotine on amygdala LTP is mediated by nAChRs and requires the activation of both $\alpha 7$ and $\beta 2$ nAChR receptors.

\section{Nicotine-induced facilitation of LTP is mediated by NMDA and GABA receptors}

In hippocampal pyramidal neuron, nicotine enhances NMDA currents during tetanus and increases the NMDA/AMPA ratio (Yamazaki et al. 2006a,b). We therefore asked the following: Is the facilitation of LTP in the amygdala mediated also by NMDA receptors? We perfused NMDA receptor antagonist D-APV (50 $\mu \mathrm{M})$ into the bath and found that D-APV completely blocked the facilitation of LTP induced by chronic nicotine exposure $(10 \mu \mathrm{g} /$
$\mathrm{mL}$ for $7 \mathrm{~d})$. In the presence of D-APV, LTP is $110 \pm 4 \%(n=6)$. This is significantly different from LTP in nicotine slices in the absence of D-APV $(147 \pm 7 \%, n=7, P<0.01)$ (Fig. 6A). In contrast to the NMDA-dependent LTP, which is induced by HFS, nicotine does not facilitate the slow-developed and NMDAindependent form of LTP induced by low-frequency stimulation (nicotine: $124 \pm 5 \%, n=5$; control: $125 \pm 6 \%, n=5$; measured 90 min after $1-\mathrm{Hz}$ stimulation, $P>0.05$ ) (Fig. 6B; Huang and Kandel 2007). These results indicate that nicotine-induced facilitation of LTP in the amygdala is mediated by the activation of NMDA receptors.

In addition to glutamatergic input, amygdala neurons are under inhibitory control from GABAergic interneurons. Blockade of this inhibition causes a higher level of depolarization and larger NMDA currents during HFS. To determine whether the facilitation induced by nicotine is affected by blockade of GABAergic inhibition, we measured LTP in slices bathed with GABA-A antagonist PTX. In the presence of PTX $(50 \mu \mathrm{M})$, no facilitation of LTP was observed in slices from mice with 7-d nicotine exposure (PTX control: $131 \pm 7 \%, n=6$; nicotine + PTX: $126 \pm 8 \%$, $n=7 ; P>0.05$ ) (Fig. 6B). This result indicates that the facilitation 


\section{A 1- day nicotine exposure}

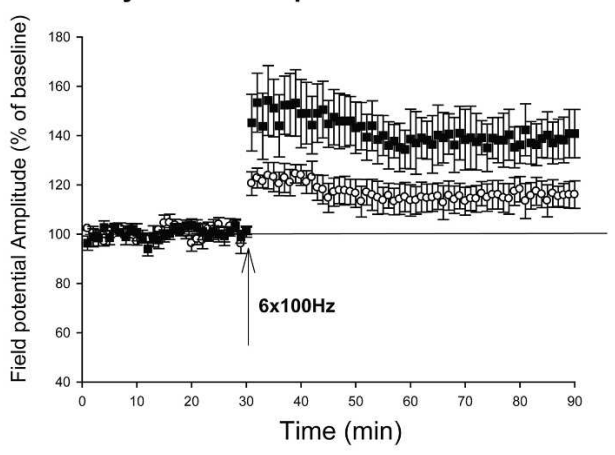

B $24 \mathrm{~h}$ after cessation of 1- day nicotine exposure

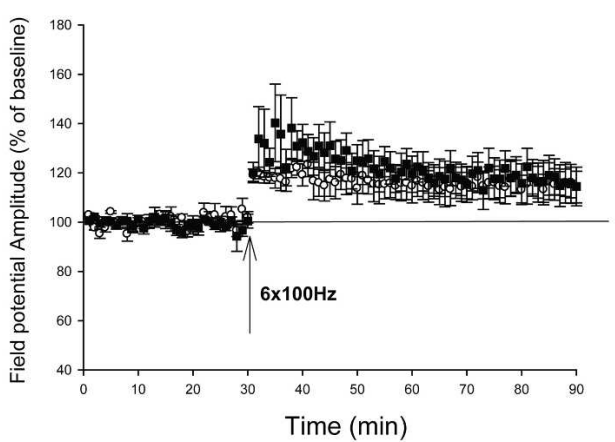

C $72 \mathrm{~h}$ after cessation of 1- day nicotine exposure

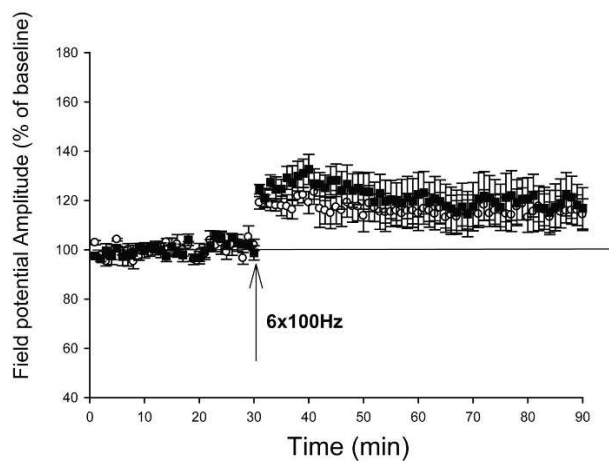

Figure 4. Synaptic facilitation induced by a short nicotine exposure. $(A)$ LTP induced by HFS is enhanced in mice exposed to nicotine for $24 \mathrm{~h}$. Closed squares indicate nicotine slices; open circles, control. (B) Twentyfour hours after cessation of nicotine (24-h nicotine treatment followed by 24 -h water), LTP in nicotine-treated mice is not significantly different from LTP in control slices. (C) The facilitation of LTP completely disappeared $72 \mathrm{~h}$ after cessation of 24-h nicotine treatment.

of LTP by nicotine in the amygdala is at least in part mediated by the removal of the inhibitory influence of GABAergic interneurons.

\section{Discussion}

\section{The concentrations of nicotine}

In this study, we used a relatively low concentration of nicotine for oral administration. We preferred to use lower nicotine doses because we are primarily interested in the molecular events that happen at the beginning of the addiction process and did not want to confound our results with molecular changes that may signify the development of tolerance. It is important to note that the doses and levels of nicotine and cotinine in various rodent studies vary greatly, but also in human smokers, cotinine blood levels vary greatly. A smoker is defined as someone with cotinine blood level $\geq 10-15 \mathrm{ng} / \mathrm{mL}$, but the levels in smokers can range between $10-15 \mathrm{ng} / \mathrm{mL}$ and $650 \mathrm{ng} / \mathrm{mL}$ or even higher. The lower dose of nicotine was previously used in several other studies. For example, Zhu et al. (2005) and Agatsuma et al. (2006) used nicotine doses of $3.125 \mu \mathrm{g} / \mathrm{mL}, 6.25 \mu \mathrm{g} / \mathrm{mL}$, and $12.5 \mu \mathrm{g} / \mathrm{mL}$ and

A

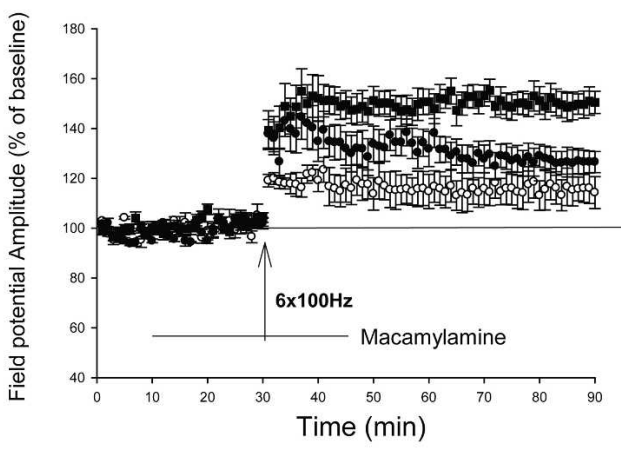

B

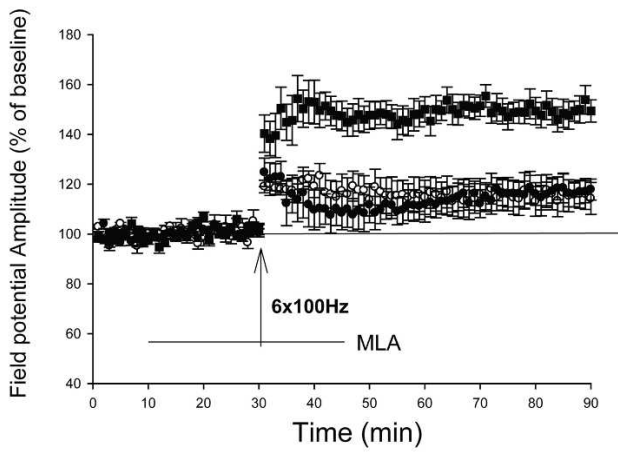

C

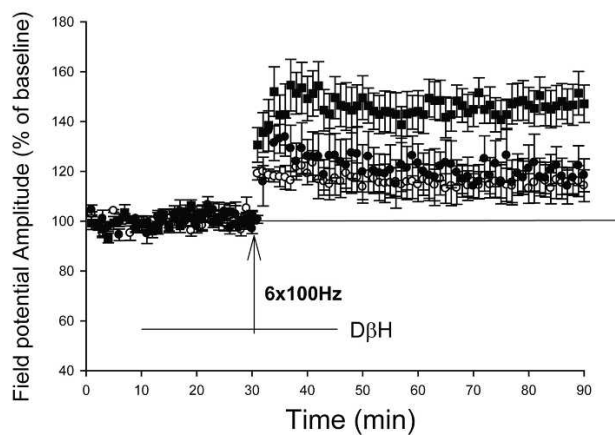

Figure 5. Nicotine-induced synaptic facilitation in the amygdala is blocked by nACh receptor antagonists. $(A)$ Bath application of general nAChR antagonist (macamylamine; indicated by the bar) blocked the synaptic facilitation induced by $7-d$ nicotine exposure. Closed squares indicate nicotine slices; closed circles, nicotine + macamylamine; and open circles, control. (B) $\alpha 7$ AChRs antagonist (MLA) blocked the synaptic facilitation induced by 7-d nicotine exposure. Closed squares indicate nicotine slices; closed circles, nicotine + MLA; and open circles, control. (C) $\beta 2$ AChRs antagonist (D $\beta H$ ) blocked the synaptic facilitation induced by 7-d nicotine exposure. Closed squares indicate nicotine slices; closed circles, nicotine $+\mathrm{D} \beta \mathrm{H}$; and open circles, control. 
A

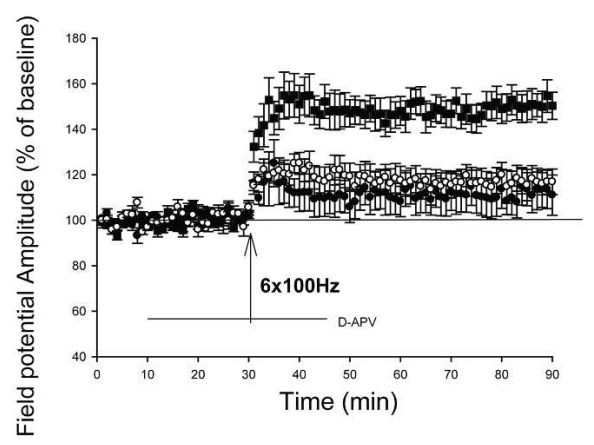

B

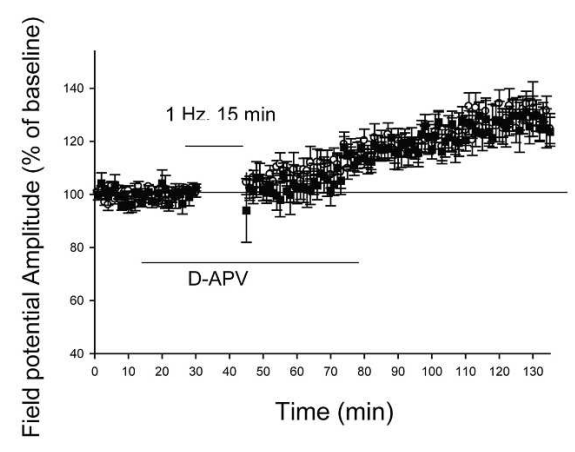

C

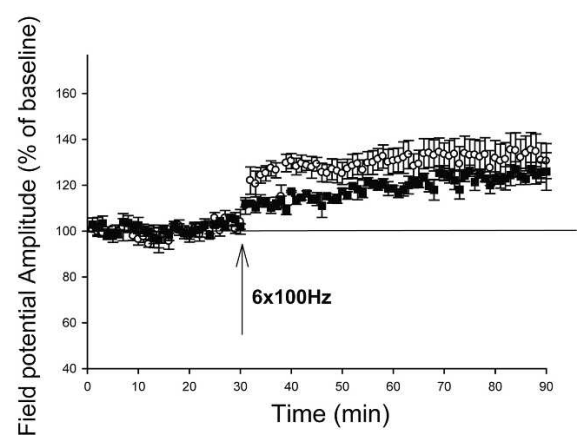

Figure 6. Synaptic facilitation induced by chronic nicotine exposure is mediated by NMDA receptors and GABAergic inhibition. $(A)$ In the presence of NMDA receptor antagonist D-APV $(50 \mu \mathrm{M})$, the nicotine-induced facilitation is completely blocked (closed squares indicate nicotine slices; closed circles, nicotine + APV; and open circles, control). (B) Nicotine exposure does not facilitate the NMDA-independent form of LTP (in the presence of D-APV) induced by $1-\mathrm{Hz}$ stimulation (closed squares indicate nicotine slices; open circles, control). (C) In the presence of GABAergic receptor antagonist picrotoxin (bath), HFS induced only a modest LTP in slices of mice exposed to nicotine for $7 \mathrm{~d}$ (closed squares), which is not significantly different from LTP in slices from mice with water control (open circles).

showed behavioral differences even for the lower doses beginning at day 4 of treatment and certainly by day 7 . Klein et al. (2004) used nicotine $10 \mu \mathrm{g} / \mathrm{mL}$ in the drinking water in an oral self-administration paradigm for $7 \mathrm{~d}$ and measured serum cotinine levels (a metabolite of nicotine that is more stable and therefore used to measure nicotine exposure). Cotinine levels in young male mice that were given nicotine $10 \mu \mathrm{g} / \mathrm{mL}$ were on average $20 \mathrm{ng} / \mathrm{mL}$, which is within the range of the levels of cotinine in human smokers (in our samples we used older mice, which are expected to have even higher levels of cotinine be- cause of a smaller liver/body ratio). Based on these studies, we chose to use $10 \mu \mathrm{g} / \mathrm{mL}$ and $25 \mu \mathrm{g} / \mathrm{mL}$ for our studies.

\section{The pathway-specific facilitation of LTP}

The LA is a key structure involved in the formation of memory for learned fear. During fear conditioning, auditory signals are sent to the LA directly via the thalamic-LA pathway (TH-LA) or indirectly via the cortical-LA pathway. One of the outputs of the $\mathrm{LA}$ is the projection to the BL (LA-BL) (Ledoux 2000). These three synaptic pathways presumably play different roles in fear memory. Cortical-LA and TH-LA may be essential for the convergence of conditioned stimulation-unconditioned stimulation in the LA, while the LA-BL pathway may play a role in the expression, but not in the acquisition, of fear memory (Amorapanth et al. 2000). In addition to having different function, the induction of LTP and LTD in these three pathways is also different. It includes a different induction threshold, a different time course, and a different amplitude of synaptic potentiation or depression. Among these pathways, the cortical-LA pathway is the most reactive (Shin et al. 2006; Huang and Kandel 2007; Sigurdsson et al. 2007). The differences in synaptic plasticity between these different pathways may be the result of different inhibitory influences caused by GABAergic interneurons (Heinbokel and Page 2000; Shin et al. 2006), different structural features in the dendritic spine, and different AMPA receptor subunits (Humeau et al. 2005, 2007; Sigurdsson et al. 2007). Behavioral studies show that the cortical-LA pathway is more critical for the storage of fear conditioning (Campeau and Davis 1995). Conditioning stimulus may recruit the cortical-LA pathway, rather than the TH-LA pathway in fear memory retrieval (Doyere et al. 2007). Consistent with these findings, we here show that nicotine facilitates LTP only in the cortical pathway, and not in the TH-LA and LA-BL pathways. This pathway-specific feature of nicotine-induced synaptic facilitation may contribute to the selective influence of nicotine on certain forms of learning and memory and anxiety disorders (Sonntag et al. 2000; Gould et al. 2004; Davis et al. 2006; Morissette et al. 2007).

\section{The role of NMDA receptors}

Nicotine exposure facilitates the induction of LTP in the hippocampus. This effect is mediated by the action of nicotine on NMDA receptors. Nicotine enhances NMDA responses during a tetanic stimulation and increases the NMDA/AMPA ratio (Yamazaki et al. 2006a,b). Here we find that nicotine-induced facilitation of LTP in the amygdala is blocked by D-APV, indicating that facilitation of LTP in the amygdala is also mediated by NMDA receptors. In the amygdala, activation of NMDA receptors is influenced by tonic inhibition from GABAergic interneurons, and GABAergic antagonists can favor the activation of NMDA receptors and facilitate the induction of LTP. In contrast, we observed in this study that nicotine-induced facilitation of LTP is blocked in slices treated with the GABA-A receptor antagonist PTX, indicating that nicotine-induced facilitation may also partially act through the attenuation of GABAergic tonic inhibition, which may be occluded in the PTX-treated slices. nACh receptors exist in GABAergic interneurons (Ji and Dani 2000; Kawai et al. 2002), and the activation of nACh receptors can influence GABAergic synaptic transmission, leading to disinhibition of pyramidal neurons in several brain regions (Mansvelder and McGehee 2002; Yamazaki et al. 2005; Zhang and Berg 2007). Therefore, it is likely that chronic exposure to nicotine activates nACh receptors located in interneurons and reduces GABAergic inhibition, which in turn facilitates the activation of NMDA receptor in pyramidal neurons, and enhances LTP. However, since the amplitude of LTP in the slices from nicotine-treated mice is much 
greater than that in the slices treated by PTX (cf. Figs. $1 \mathrm{~A} 2$ and 6C), the removal of GABAergic inhibition may not be the sole factor contributing to the nicotine-induced facilitation of LTP. Other nicotine-induced synaptic changes such as increased glutamate release from presynaptic terminal and increased $\mathrm{Ca}^{2+}$ influx through the voltage-dependent calcium channel postsynaptically may also contribute to the facilitation effect (Mansvelder and McGehee 2000; Dani et al. 2001; Welsby et al. 2006).

\section{The time course of nicotine-induced facilitation of LTP}

Psychostimulants trigger multiple and complex neural adaptations that develop at different time courses ranging from hours to days. One important issue in the study of addiction is to determine a time course for the action of these drugs. When nicotine is administered p.o. to mice, they consume it in bouts, which mimics smoking behavior in humans. The up-regulation of nAChRs in the brain varies according to the time period of exposure to nicotine (Vezina et al. 2007). Different time periods of nicotine exposure could therefore lead to a different time course of plastic changes in synapses. In most previous studies on the synaptic plasticity, nicotine was administered intraperitoneally (i.p.) and by subcutaneous injection, or by acute bath application into a slice chamber (Fujii et al. 1999; Matsuyama et al. 2000; Welsby et al. 2006; Yamazaki et al. 2006a; Nakauchi et al. 2007); the time course of the effect produced by chronic oral administration is unknown. We find in this study that chronic oral exposure to nicotine can produce different phases of synaptic facilitation, depending on the duration of exposure time. A longer period of exposure to nicotine produces a longer-lasting facilitation. In mice treated with nicotine for $7 \mathrm{~d}$, the facilitation remains intact $24 \mathrm{~h}$ and $72 \mathrm{~h}$ after cessation of nicotine, but it completely disappears $8 \mathrm{~d}$ after nicotine was stopped. This longlasting facilitation of LTP induced by nicotine is consistent with previous findings in the hippocampal neurons, which show that the enhancement of NMDA current induced by chronic nicotine exposure (10 d i.p. administration) lasts for $\sim 8 \mathrm{~d}$ (Yamazaki et al. 2006b). In contrast, we find that a short exposure to nicotine (24 h) induces a short-lasting facilitation of synaptic plasticity that completely disappears $24 \mathrm{~h}$ after cessation to nicotine. This exposure duration effect on LTP that is induced by nicotine in the amygdala is similar to the synaptic facilitation induced by $5-\mathrm{HT}$ in the connection between sensory and motor neurons of Aplysia, in which a single, short exposure to 5-HT induces shortlasting facilitation (STF) and repeated exposures to 5-HT produces an enduring form of synaptic facilitation (LTF) (Hawkins et al. 2006).

\section{Materials and Methods}

Male C57BL6/J mice (6- to 12-wk-old) (Jackson Laboratories, Bar Harbor, Maine) were used for all experiments. Mice were kept in clear plastic cages $(29.2 \times 19 \times 12.7 \mathrm{~cm}, \mathrm{~N} 10$ cage, Ancare $)$ in groups of five with ad libitum food (Prolab IsoPro RMH3000, PMI Nutrition International) and water (autoclaved tap water). Mice were kept at a 12-h day/night cycle.

Mice were quickly decapitated, the whole brain was placed in ice-cold ACSF (artificial cerebrospinal fluid), and a block of tissue containing the amygdala was removed. Coronal sections $(400 \mu \mathrm{M})$ were cut and transferred to an interface chamber (Fine Science Tools). Slices were submerged and constantly perfused with ACSF at a rate of $2 \mathrm{~mL} / \mathrm{min}$ and bubbled with $95 \% \mathrm{O}_{2}$ and $5 \% \mathrm{CO}_{2}$. The composition of ACSF was as follows (in $\mathrm{mM}$ ): 124 $\mathrm{NaCl}, 1.2 \mathrm{MgSO}_{4}, 4 \mathrm{KCl}, 1.0 \mathrm{NaH}_{2} \mathrm{PO}_{4}, 2 \mathrm{CaCL}_{2}, 26 \mathrm{NaHCO}_{3}$, and 10 D-glucose. In some experiments, GABAergic antagonist PTX $(50 \mu \mathrm{M})$ was present in the perfusion solution. The temperature of the slice was maintained at $27^{\circ} \mathrm{C}$. Experiments were started 2-3 $\mathrm{h}$ after slices were dissected.

Extracellular recordings were made using ACSF-filled glass electrodes (1-3 M). Stimuli were delivered at a rate of one per minute $(0.017 \mathrm{~Hz}, 0.05-\mathrm{msec}$ pulse duration) through concentric bipolar stainless steel electrodes $(25-\mu \mathrm{M}$ wire diameter, CBBRC75, FHC). To produce LTP in the cortical-LA synaptic pathway, the stimulating electrodes were placed in the external capsule (EC), which contained fibers from the auditory cortex to the LA (EC-LA). To produce LTP in the TH-LA pathway, the stimulating electrodes were placed in thalamic afferent fiber to the LA, which is located in the ventral part of the striatum just above the central nucleus of the amygdala (Huang and Kandel 2007). To record from EC-LA and TH-LA pathways, recording electrodes were placed in the LA. To produce LTP in the LA-BL synaptic pathway, the stimulating electrodes were placed in the LA, and the recording electrodes were placed in the basolateral subdivision of amygdala. The stimulation intensity was adjusted to evoke the field potential that was $\sim 50 \%-60 \%$ of maximal amplitude. Baseline values were acquired over a period of $30 \mathrm{~min}$ before giving the LTP-inducing stimulation. In all synaptic pathways tested in this study, LTP was elicited by $3 \times 2$ trains of $100-\mathrm{Hz}$ tetanus (with $10-\mathrm{sec}$ intertrain interval) 3 min apart. The pulse duration of stimulation during tetanus is $0.1 \mathrm{msec}$. Changes in synaptic strength were expressed relative to the normalized baseline (mean \pm SEM). Statistical comparisons were performed using student's $t$-test.

Nicotine hydrogen tartrate salt (Sigma) was dissolved in drinking water $(2,10$, and $25 \mu \mathrm{g} / \mathrm{mL})$ and administered continuously in the drinking water for $1 \mathrm{~d}$ or $7 \mathrm{~d}$ prior to the experiment day. For bath application, the following drugs were made in water and stored as concentrated stock solution and diluted 1000fold when applied to the perfusion solution: D-APV (Sigma), mecamylamine hydrochloride (Sigma), DßH (Sigma), and MLA (Tocris).

\section{Acknowledgments}

This work was supported by the Howard Hughes Medical Institute, the New York Psychiatric Institute, and NIDA grant SR01DA024001-02.

\section{References}

Agatsuma, S., Lee, M., Zhu, H., Chen, K., Shih, J.C., Seif, I., and Hiroi, N. 2006. Monoamine oxidase A knockout mice exhibit impaired nicotine preference but normal responses to novel stimuli. Hum. Mol. Genet. 15: 2721-2731.

Amorapanth, P.A., Ledoux, J.E., and Nader, K. 2000. Different lateral amygdala outputs mediate reactions and actions elicited by a fear-arousing stimulus. Nat. Neurosci. 3: 74-79.

Bauer, E.P., Schafe, G.E., and Ledoux, J.E. 2002. NMDA receptors and L-type voltage-gated calcium channels contribute to long-term potentiation and different components of fear memory formation in the lateral amygdala. J. Neurosci. 22: 5239-5249.

Campeau, S. and Davis, M. 1995. Involvement of subcortical and cortical afferents to the lateral nucleus of the amygdala in fear conditioning measured with fear-potentiated startle in rats trained concurrently with auditory and visual conditioned stimuli. $J$. Neurosci. 15: 2312-2327.

Dani, J.A. Ji, D., and Zhou, F-M. 2001. Synaptic plasticity and nicotine addiction. Neuron 31: 349-352.

Davis, J.A., Porter, J., and Gould, T.J. 2006. Nicotine enhances both foreground and background contextual fear conditioning. Neurosci. Lett. 394: 202-205.

Doyere, V., Debiec, J., Monfils, M.-H., Schafe, G.E., and Ledoux, J.E. 2007. Synapse-specific reconsolidation of distinct fear memories in the lateral amygdala. Nat. Neuroscience 10: 414-416.

Fujii, S., Ji, Z., Morita, N., and Sumikawa, K. 1999. Acute and chronic nicotine exposure differently facilitate the induction of LTP. Brain Res. 846: 137-143.

Fujii, S., Ji, Z., and Sumikawa, K. 2000. Inactivation of $\alpha 7$ ACh receptors and activation of non- $\alpha 7$ ACh receptors both contribute to long-term potentiation induction in the hippocampal CA1 region. Neurosci. Lett. 286: 134-138.

Gaimarri, A., Moretti, M., Riganti, L., Zanardi, A., Clementi, F., and Gotti, C. 2007. Regulation of neuronal nicotic receptor traffic and expression. Brain Res. Rev. 55: 134-143.

Gould, T.J. and Higgins, J.S. 2003. Nicotine enhances contextual fear conditioning in C57BL/6J mice at 1 and 7 days post-training. Neurobiol. Learn. Mem. 80: 147-157. 
Gould, T.J., Feiro, O., and More, D. 2004. Nicotine enhances trace cued fear conditioning but not delay cued fear conditioning in C57BL/6 mice. Behav. Brain Res. 155: 167-173.

Hawkins, M., Kandel, E.R., and Bailey, C.H. 2006. Molecular mechanism of memory storage in Aplysia. Biol. Bull. 210: 174-191.

Heinbokel, T. and Page, H.-C. 2000. Input-specific long-term depression in the lateral amygdala evoked by theta frequency stimulation. $J$. Neurosci. 20: RC68.

Hill Jr., J.A., Zoli, M., Bourgeois, J.P., and Changeux, J.P. 1993. Immunocytochemical localization of a neuronal nicotinic receptor: The $\beta 2$-subunit. J. Neurosci. 13: 1551-1568.

Huang, Y.-Y. and Kandel, E.R. 1998. Postsynaptic induction and PKA-dependent expression of LTP in the lateral amygdala. Neuron 21: $169-178$.

Huang, Y.-Y. and Kandel, E.R. 2007. Low-frequency stimulation induces a pathway-specific late phase of LTP in the amygdala that is mediated by PKA and dependent on protein synthesis. Learn. Mem. 14: $497-503$.

Humeau, Y., Herry, C., Kemp, N., Shaban, H., Fourcaudot, E., Bissiere, S., and Luthi, A. 2005. Dendritic spine heterogeneity determines afferent-specific hebbian plasticity in the amygdala. Neuron 45: $119-131$.

Humeau, Y., Reisel, D., Johnson, A.W., Borchardt, T., Jenesen, V., Gebhardt, C., Bosch, V., Gass, P., Bannerman, D.M., Good, M.A., et al. 2007. A pathway-specific function for different AMPA receptor subunits in amygdala long-term potentiation and fear conditioning. J. Neurosci. 27: 10947-10956.

Ji, D. and Dani, J.A. 2000. Inhibition and disinhibition of pyramidal neurons by activation of nicotinic receptors on hippocampal interneurons. J. Neurophysiol. 83: 2682-2690.

Kawai, H., Zago, W., and Berg, D.K. 2002. Nicotine $\alpha 7$ receptor clusters on hippocampal GABAergic neurons: Regulation by synaptic activity and neurotrophins. J. Neurosci. 22: 7903-7912.

Klein, R.C. and Yakel, J.L. 2006. Functional somato-dendritic $\alpha 7$-containing nicotinic acetylcholine receptors in the rat basolateral amygdala complex. J. Physiol. 576: $865-872$.

Klein, L.C., Stine, M.M., Vandenbergh, D.J., Whetzel, C.A., and Kamens, H.M. 2004. Sex differences in voluntary oral nicotine consumption by adolescent mice: A dose-response experiment. Pharmacol. Biochem. Behav. 78: 13-25.

Ledoux, J.E. 2000. Emotion circuits in the brain. Annu. Rev. Neurosci. 23: $155-184$

Levin, E.D. 1992. Nicotinic systems and cognitive function. Psychopharmacology 1992: 417-431.

Miller, R.P., Rotenberg, K.S., and Adir, J. 1977. Effect of dose on the pahrmacokinetics of intravenous nicotine in the rat. Drug Metab. Dispos. 5: 436-443.

Mansvelder, H.D. and McGehee, D.S. 2000. Long-term potentiation of excitatory inputs to brain reward areas by nicotine. Neuron 27: 349-357.

Mansvelder, H.D. and McGehee, D.S. 2002. Cellular and synaptic mechanisms of nicotine addiction. J. Neurobiol. 53: 606-617.

Matsuyama, S., Matsumoto, A., Enomoto, T., and Nishizaki, T. 2000. Activation of nicotinic acetylcholine receptors induces long-term potentiation in vivo in the intact mouse dentate gyrus. Eur. J. Neurosci. 12: 3741-3747.

Morissette, S.B., Tull, M.T., Gulliver, S.B., Kamholz, B.W., and Zimering, R.T. 2007. Anxiety, anxiety disorders, tobacco use, and nicotine: A critical review of interrelationships. Psychol. Bull. 133: 245-272.

Nakauchi, S., Brennan, R., Boulter, J., and Sumikawa, K. 2007. Nicotine gate long-term potentiation in the hippocampal CA1 region via the activation of $\alpha 2$ nicotine ACh receptors. Eur. J. Neurosci. 25: $2666-2681$.
Rammes, G., Stecklers, T., Schuts, G., Zieglgannsberger, W., and Luts, B. 2000. Synaptic plasticity in the basolateral amygdala transgenic mice expression dominant-negative cAMP response element-binding protein (CREB) in forebrain. Eur. J. Neurosci. 12: 2534-2546.

Rogan, M.T., Staubli, U.V., and Ledoux, J.E. 1997. Fear conditioning induces associative long-term potentiation in the amygdala. Nature 390: 604-607.

Schroeder, B.W. and Shinick-Gallagher, P. 2005. Fear learning induces persistent facilitation of amygdala synaptic transmission. Eur. J. Neurosci. 22: 1775-1783.

Shin, R.M., Tsvetkov, E., and Bolshakov, V.Y. 2006. Spatiotemporal asymmetry of associative synaptic plasticity in fear conditioning pathways. Neuron 53: 883-896.

Sigurdsson, T., Doyere, V., Cain, C.K., and Ledoux, J.E. 2007. Long-term potentiation in the amygdala: A cellular mechanism of fear learning and memory. Neuropharmacology 52: 215-227.

Socci, D.J., Sanberg, P.R., and Arendash, G.E. 1995. Nicotine enhances Morris water maze performance of young and aged rats. Neurobiol. Aging 16: 857-860.

Sonntag, H., Wittechen, H.U., Hofler, M., Kessler, R.C., and Stein, M.B. 2000. Are social fears and DSM-IV social anxiety disorder associated with smoking and nicotine dependence in adolescent and young adults? Eur. Psychiatry 15: 67-74.

Tsvetkov, E., Carlezon, W.A., Benes, F.M., Kandel, E.R., and Bolshakov, V.Y. 2002. Fear conditioning occludes LTP-induced presynaptic enhancement of synaptic transmission in the cortical pathway to the lateral amygdala. Neuron 34: 289-300.

Vezina, P., McGehee, D.S., and Green, W.N. 2007. Exposure to nicotine and sensitization of nicotine-induced behavior. Prog. Neuropsychopharmacol. Biol. Psychiatry 31: 1625-1638.

Welsby, P., Rowan, M., and Anwyl, R. 2006. Nicotine receptor-mediated enhancement of long-term potentiation involves activation of metabotropic glutamate receptors and ryanodine-sensitive calcium stores in the dentate gyrus. Eur. J. Neurosci. 24: 3109-3118.

Welsby, P., Rowan, M., and Anwayl, R. 2007. $\beta$-Amyloid blocks high frequency stimulation induced LTP but not nicotine enhanced LTP. Neuropharmacology 53: 188-195.

Yamazaki, Y., Hamaeue, N., and Sumikawa, K. 2002. Nicotine compensations for the loss of cholinergic function to enhance long-term potentiation induction. Brain Res. 946: 148-152.

Yamazaki, Y., Jia, Y., Hamaue, N., and Sumikawa, K. 2005. Nicotine-induced switch in the nicotinic cholinergic mechanisms of facilitation of long-term potentiation induction. Eur. J. Neurosci. 22: $845-860$.

Yamazaki, Y., Jia, Y., Nu, R., and Sumikawa, K. 2006a. Nicotine exposure in vivo induces long-lasting enhancement of NMDA receptor-mediated currents in the hippocampus. Eur. J. Neurosci. 23: 1819-1828.

Yamazaki, Y., Fujii, S., Jia, Y., and Sumikawa, K. 2006b. Nicotine withdrawal suppresses nicotine modulation of long-term potentiation induction in the hippocampal CA1 region. Eur. J. Neurosci. 24: 2903-2916.

Zhang, J. and Berg, D.K. 2007. Reversible inhibition of GABA-A receptors by $\alpha 7$-containing nicotinic receptors on the vertebrate postsynaptic neurons. J. Physiol. 579: 753-763.

Zhu, H., Lee, M., Guan, F., Agatsuma, S., Scott, D., Fabrizio, K., Fienberg, A.A., and Hiroi, N. 2005. DARPP-32 phosphorylation opposes the behavioral effects of nicotine. Biol. Psychiatry 58: 981-989.

Received February 25, 2008; accepted in revised form June 4, 2008. 


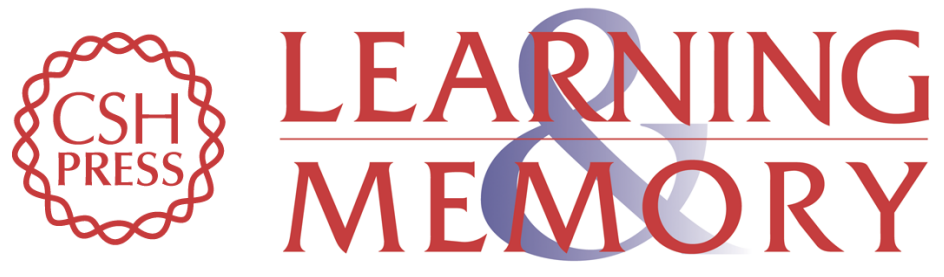

\section{Chronic nicotine exposure induces a long-lasting and pathway-specific facilitation of LTP in the amygdala}

Yan-You Huang, Eric R. Kandel and Amir Levine

Learn. Mem. 2008, 15:

Access the most recent version at doi:10.1101/lm.975308

References This article cites 47 articles, 8 of which can be accessed free at: http://learnmem.cshlp.org/content/15/8/603.full.html\#ref-list-1

License

Email Alerting Receive free email alerts when new articles cite this article - sign up in the box at the Service top right corner of the article or click here. 